\title{
Junction formation with HWCVD and TCAD model of epitaxial back contact solar cell
}

\author{
Tasmiat Rahman, Amirjan Nawabjan, Antulio Tarazona, Darren M Bagnall, and Stuart A Boden
}

\begin{abstract}
In this work we present morphological and electrical characteristics of a junction formed of Si P-type films deposited on an $\mathbf{N}$-type silicon wafer using a hot wire chemical vapour deposition tool. We describe the fabrication process, and study the influence of diborane flow and post-process annealing in improving junction characteristics. Our morphological studies undertaken using atomic force microscopy show that the initial deposition suffered from voids rather than being a uniform film, however this improves significantly under our annealing treatment. The improvement in morphology was observed in the electrical characteristics, with estimated $V_{o c}$ doubling and rectification of the junction improving by several orders of magnitude. Fitting of the current-voltage curves to a two diode model, showed that increasing the diborane flow in the process helps reduce the saturation current and ideality factors, whilst increasing the shunt resistance. ECV and QSSPC measurements are used to characterise the deposited films further. A solar cell device with a silicon epitaxy emitter is modelled using industry standard 3D modelling tools and input parameters from experimental data, and the impact of defects is studied. A potential efficiency approaching $25 \%$ is shown to be feasible for an optimised device.
\end{abstract}

Keywords-HWCVD, Back Contact Solar Cell, TCAD

\section{INTRODUCTION}

Advances in photovoltaics have led to interest in back contact solar cells which have the advantage of enabling the utilisation of the entire front surface for efficient light trapping structures. Moreover, this architecture lends itself to the use of the device as a sub-cell in a tandem stack with emerging materials such as perovskites. The cell contacts can be interdigitated to improve the performance by increasing the junction area. One method of achieving this is using a spin on dopant process to form diffused junctions at high temperature. In this work, we explore the use of epitaxially-grown silicon layers to form the P-type regions in an interdigitated back contact (IBC) solar cell. The IBC design has a number of advantages over conventional solar cell designs. Complete elimination of front metal contacts enable the individual optimization of optical and electrical properties. Absence of front metal contacts also leads to higher short circuits due to absence of shadowing loss, and also lower resistive losses [1]. The cell design offers easier interconnection and increased packing density within a module. Furthermore, the approach improves

T. Rahman and S.A. Boden are with Electronics and Computer Science, University of Southampton, Southampton, UK, e-mail: t.rahman@soton.ac.uk

A. Nawabjan is with the Department of Electronics and Computer Engineering, Universiti Teknologi Malaysia, Johor, Malaysia

A. Tarazona is with EcherKon Technologies Ltd, West Sussex, UK

D.M. Bagnall is with School of Photovoltaic and Renewable Energy Engineering, University of New South Wales, NSW, Australia aesthetics, increasing the likelihood of large scale adoption in building integrated PV [2]. The concept has been adopted commercially for large-area cells by, for example Sunpower, who have demonstrated power conversion efficiencies of over $25 \%$ [3].

Silicon epitaxy is a well known process in microelectronics and thin film solar cells [4]-[6]. However it is regarded as a novel process in bulk crystalline silicon photovoltaics. Epitaxial emitters possess some advantages over normal diffused emitters including short deposition times $\left(0.2-2 \mu \mathrm{m} \mathrm{min}^{-1}\right.$ using APCVD), and a more controllable emitter profile. In addition, there is no wet chemical etching required after the deposition, contact resistance can be optimized depending on the metallisation process, and it has a potentially lower thermal budget compared to diffusion processes. Recaman Payo et. al deposited high quality boron doped epitaxy using LPCVD which resulted in a $22.1 \%$ efficient IBC solar cell [5]. They also showed that they can selectively grow the epitaxial layer. Rachow et al. produced a $21 \%$ efficient PERL solar cell by using phosphorus doped epitaxial emitter grown by APCVD [7]. This proves that epitaxially grown emitters can potentially replace diffused emitters in high performance IBC solar cells to simplify the process flow and hence reduce costs.

In this work we look at the fabrication process of the epitaxial layer using a commercial hot wire chemical vapour deposition (HWCVD) system built by Echerkon Technologies Ltd. This technique can be scaled up to large area manufacturing at low cost compare to other techniques [8]. HWCVD is also capable of producing epitaxial films at deposition rates in excess of $100 \mathrm{~nm} \mathrm{~min}^{-1}$ at relatively low temperatures, i.e. below $700^{\circ} \mathrm{C}$ [9]. We analyse the morphology and electrical characteristics of the films under varying annealing treatments and impurity doping. The morphology analysis consists of atomic force microscopy (AFM), from which we can quantify the surface roughness and grain formation. The films are then metallised and current-voltage characteristics are measured under dark conditions. A two diode model is used to quantify the effectiveness of the boron doped films as emitters in solar cells.

Simulation of solar cells plays an important role to assess the performance of the device as improvements to the design are made. Many device simulators have been used intensively to simulate solar cell designs including IBC solar cells. Savin et al. performed TCAD Sentaurus device simulations on black silicon IBC cell designs [10]. Jeong et al. also used TCAD Sentaurus device simulations for a nanocone textured IBC solar cell which showed close agreement with the fabricated device [11]. Zin et al. used PC2D to investigate the effect of 
(a)

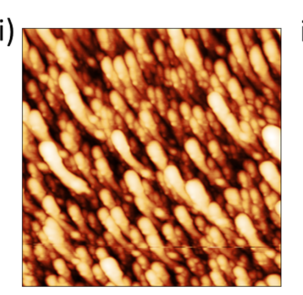

(b) i)

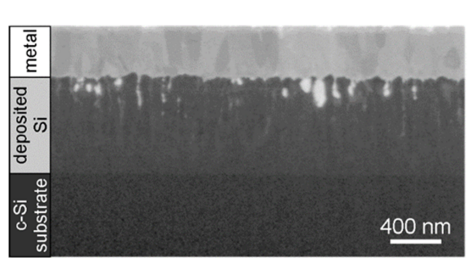

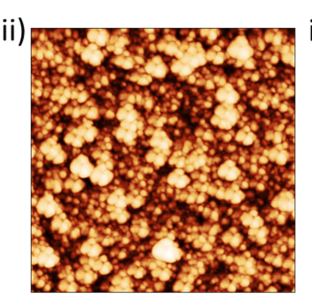

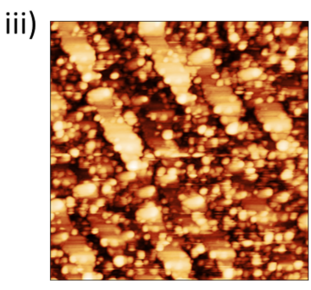

ii)

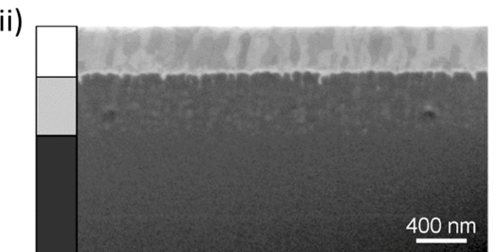

Fig. 1: a) AFM imaging of the deposited silicon film (no metal) un-annealed (i), 2 hour annealed (ii) and 4 hour annealed (iii). Processing of the image has been done to level the base prior to any statistical analysis. The AFM window is $2.5 \mu \mathrm{m}$ by $2.5 \mu \mathrm{m}$. b) Cross-section of deposited film and metal, created and imaged using Ga focused ion beam. Cross-sectional surface normal is at $36^{\circ} \mathrm{C}$ with respect to the incident beam. The un-annealed case (i) and 4 hour annealed case (ii) is shown.

wafer thickness and pitch size on IBC cell performance [12], and Xinbo et al. used Quokka to simulate IBC solar cells [2]. In this work Synopsys TCAD is used to to simulate the performance of IBC solar cells with epitaxial emitters.

\section{EXPERIMENTAL JUNCTION FORMATION}

\section{A. Fabrication Process}

A pn junction is formed by depositing a P-type silicon film onto a 4" N-type silicon wafer, and then evaporating metal on both sides. HWCVD uses vapour-phase epitaxy, where the epitaxial layer is formed by chemical reaction between precursor gaseous compounds. In this work, silane $\left(\mathrm{SiH}_{4}\right)$ was used as a precursor gas for the epitaxial growth on (100) oriented $\mathrm{Si}$. In-situ doping was performed by flowing diborane $\left(B_{2} H_{6}\right)$ as the epitaxial growth is taking place, which leads to a P-type film. The total pressure of the chamber is 0.01 mbar. The wire temperature is set to $2100^{\circ} \mathrm{C}$ and the substrate temperature set to $550^{\circ} \mathrm{C}$. The deposition time is fixed at 45 minutes. The substrate (4" N-type, Fz, 1-10 $\Omega \mathrm{cm},\langle 100\rangle$ ) was cleaned using piranha etch solution, then briefly immersed in 20:1 HF solution to strip any native oxide and prepare the surface for growth. For the case of blanket deposition, the next step is the use of HWCVD. For the case of selective deposition, a $300 \mathrm{~nm}$ thermal oxide is first grown on the top surface and photo-lithography is used to make finger openings down to $500 \mu \mathrm{m}$ wide. For $\mathrm{Si}$ deposition, the silane flow rate was fixed at $20 \mathrm{sccm}$, and diborane (diluted with $10 \% \mathrm{H}_{2}$ ) flow rates of 10,15, and $20 \mathrm{sccm}$ were used to investigate the effect on the final doping level of the emitter. The resulting emitter had a thickness of approximately $1 \mu \mathrm{m}$ (measured using scanning electron microscopy). Post processing of the films was undertaken by annealing for different times (30 minutes, 2 hours and 4 hours) in a tube furnace at $1000^{\circ} \mathrm{C}$ under inert gas. Aluminum contacts were deposited on both the bottom (n-type substrate) and top (p-type film) surfaces using e-beam evaporation with a thickness of $500 \mathrm{~nm}$. Unless specified, the results shown are for blanket deposition.

\section{B. Morphology}

The morphology of the boron doped emitter was measured using AFM. The images were pre-processed to level all the data, such that comparisons between them can be made. Fig. 1a illustrates the surface profiles of un-annealed, 2 hour annealed and 4 hour annealed samples. It can been seen that in the un-annealed case an array of columns have formed, with a prevalence of void areas, rather than a blanket epitaxial layer. By applying post annealing to the film, there is a coalescence of the columns leading to a more dense film with reduction in voids. This behaviour is not only observable qualitatively from the images, but it is also possible to quantify this with the RMS value of the height irregularities $\left(R_{q}\right)$. This is a means to quantify surface roughness. We find that for the unannealed sample, $R_{q}=9.6 \mathrm{~nm}$, which reduces to $R_{q}=8.1$ $\mathrm{nm}$ after 2 hours annealing, and reduces further to $R_{q}=6.1$ $\mathrm{nm}$ after 4 hours annealing. Furthermore, the maximum height from the surface profile reduces from $73 \mathrm{~nm}$ to $53 \mathrm{~nm}$ after a 4 hour anneal. This can be attributed to the film becoming denser. This is further supported by the focused ion beam (FIB NVision40, Carl Zeiss) images shown in Fig. 1b. A gallium ion source is used, and a trench is milled to expose a crosssection of the layer. The cross-section is polished further by the Ga FIB $(30 \mathrm{keV})$ beam and then imaged with the same beam. We observe the contrast in grain structure in the unannealed case, however this contrast significantly reduces in the annealed case. The interface has shifted up in the annealed case, which indicates recrystallisation. Furthermore, shorter tendrils of metal are observed in the annealed case due to columnar grains fusing together, i.e. shallower crevasses and densification. These results show that the deposited film, prior to any annealing treatments, suffers from poor conformity of the initial seed layer to the substrate. This results in quick growth in the seed regions, and voids elsewhere. Annealing rectifies this problem as the film fuses to the orientation of the substrate, highlighted by the ribbon type features observable in the AFM image of the 4 hour annealed sample. Evidence of 

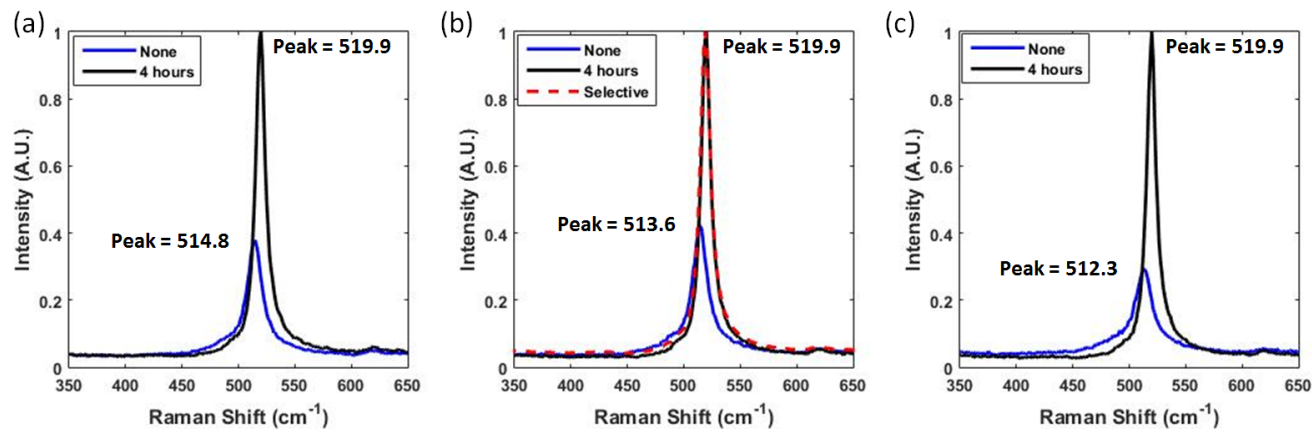

Fig. 2: Raman spectroscopy of the deposited film (unannealed and $4 \mathrm{~h}$ annealed) for varying silane/diborane ratios (a) 20/10 sccm, (b) $20 / 15 \mathrm{sccm}$ and (c) 20/20 sccm. The characteristics of selectively deposited material is illustrated by the red dashed line in $b)$.

crystallinity in the annealed layer can be obtained using Raman spectroscopy. This technique can distinguish between thin films of amorphous, polycrystalline, or monocrystalline silicon based on the peak of the Raman shift. Silicon-silicon bonds are symmetrical and result in strong Raman scattering. As a result, a sharp Raman peak is formed at $520 \mathrm{~cm}^{-1}$. Polysilicon and amorphous silicon on the other hand are less orderly which leads to typical peak formed at $515 \mathrm{~cm}^{-1}$ for poly-Si, and a broad Raman band centered around $480 \mathrm{~cm}^{-1}$ for amorphous silicon that is readily distinguishable from that of crystalline silicon [13]. Raman spectra of the HWCVD-deposited emitter layer before and after a 4 hour anneal are presented in Fig. 2. The Raman spectrum of the as-deposited HWCVD sample exhibits a broad peak at $515 \mathrm{~cm}^{-1}$ confirming that layer is indeed polycrystalline. However, by annealing the samples, the peak moves towards the single crystal silicon peak of $520 \mathrm{~cm}^{-1}$. The broaden spectral peak compared to crystalline silicon even after annealing can be explained by the incorporation of a large concentration of dopants into the silicon host lattice that causes lattice distortion [14]. Annealing improves the quality of the film by inducing solid phase crystallisation. We are currently upgrading the HWCVD tool to undertake depositions in higher temperature of $750{ }^{\circ} \mathrm{C}$; this will improve the conformity in the initial growth of the seed layer thereby producing an epitaxial film from the start and reducing the need for post annealing. Optimisation of pregrowth surface treatments could also improve the quality of the as-grown film [15]. Fig. 2b shows that both blanket deposition and selective deposition can result in films of high crystallinity after annealing. This illustrates the feasibility of the HWCVD process for IBC PV fabrication which may require the need for emitter finger formation after back surface field formation.

\section{Dark IV measurements}

The current voltage measurements are taken under dark conditions using a simple Keithley set-up and LabVIEW interface. Fig. 3 illustrates the current-voltage characteristics for junctions under different annealing treatment and doping conditions. To further analyse the influence of the impurity doping, a two diode model is used to fit the IV characteristics of the 3 different diborane flow treatments. An open source tool [16] is used to fit the experimental data to equation 1 derived by Rauschenbach et al. [17].

$$
J=J_{01} \exp ^{\frac{q\left(V-J R_{s}\right)}{n_{1} k T}}+J_{02} \exp ^{\frac{q\left(V-J R_{s}\right)}{n_{2} k T}}+\frac{V-J R_{s}}{R_{p}}
$$

Where: $J_{01}, J_{02}$ are the reverse saturation currents and $n_{1}, n_{2}$ are the ideality factors for the first (ideal) and second diode (non-ideal) in the model respectively. $R_{s}$ and $R_{p}$ represent the series and shunt resistance in the equivalent circuit. The results are summarized in Table I. It can be seen that increasing the diborane flow rate improves the diode performance by reducing the saturation currents and increasing the shunt resistance. We find that the estimated $V_{o c}$ (calculated by shifting the darkIV with an assumed photocurrent density of $38 \mathrm{~mA} \mathrm{~cm}^{-2}$ ) significantly increases from an average value of $340 \mathrm{mV}$ to $610 \mathrm{mV}$ after annealing for 4 hours. Alongside this, there is also a significant increase in the rectification ratio (taken at 1V) from an average value of 13 for the un-annealed case to 1900 in the 4 hour annealed case. The improvements observed under annealing are in agreement with the morphology results, as the carrier mobility will increase as the film becomes more uniform and less porous. A reduction in the ideality factor of the junction is also observable by increasing the diborane flowrate to $20 \mathrm{sccm}$. This could be due to a lower saturation current of the second diode in the two diode model. This suggests less recombination is occurring in the depletion region as it has narrowed due to increasing boron doping levels. The increase in shunt resistance observed could be a result of more uniform doping laterally as the dopant flow rate increases. We note that the absolute values of $\mathrm{J} 0$ will be higher in the diode tested here due to the large amount of metal-silicon contact area compared to a solar cell where much of the surface will be covered with a passivation layer.

TABLE I: Diode parameters for varying diborane flow rates with a $4 \mathrm{~h}$ anneal time.

\begin{tabular}{ccccccc}
\hline $\begin{array}{c}\text { Ratio } \\
(\mathrm{sccm})\end{array}$ & $\begin{array}{c}J_{01} \\
\left(\mathrm{pAcm}^{-2}\right)\end{array}$ & $\begin{array}{c}J_{02} \\
\left(\mathrm{nAcm}^{-2}\right)\end{array}$ & $\begin{array}{c}R_{s} \\
\left(\Omega \mathrm{cm}^{-2}\right)\end{array}$ & $\begin{array}{c}R_{p} \\
\left(\Omega \mathrm{cm}^{-2}\right)\end{array}$ & $n_{1}$ & $n_{2}$ \\
\hline $20 / 10$ & 2.2 & 520 & 2.9 & 730 & 1 & 2.6 \\
$20 / 15$ & 3.4 & 180 & 10 & 2700 & 1 & 2.4 \\
$20 / 20$ & 0.24 & 96 & 5.2 & 31743 & 1 & 1.9 \\
\hline
\end{tabular}



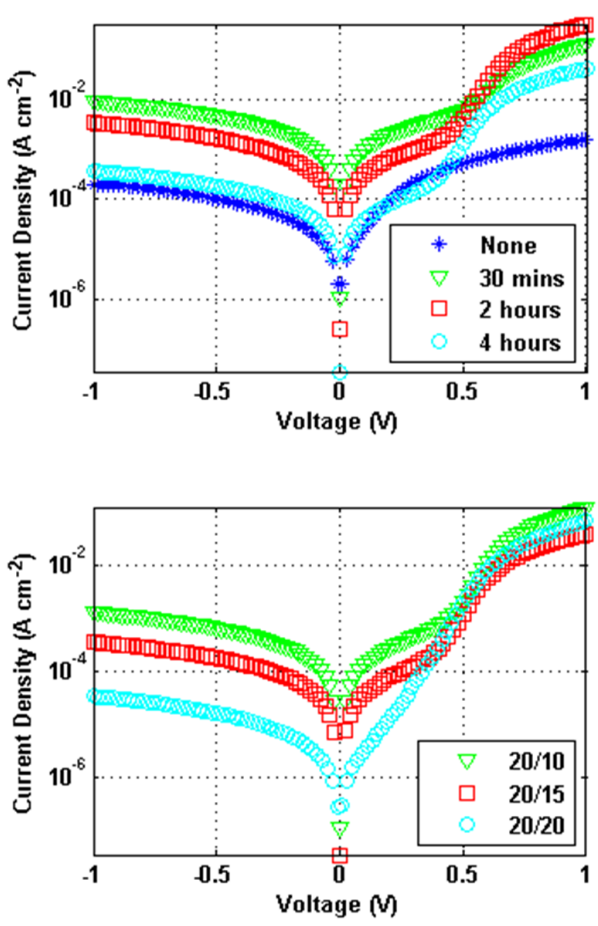

Fig. 3: a) IV characteristics for varying anneal time with 20/15 silane/diborane ratio. b) IV characteristics for varying silane/diborane ratio with $4 \mathrm{~h}$ anneal time.

\section{Doping Profile}

Fig 4 shows the boron concentration in the film for an asdeposited (unannealed) case and a post $4 \mathrm{~h}$ anneal $\left(1000^{\circ} \mathrm{C}\right)$ case. This was measured using the electrochemical capacitance voltage (ECV) technique (WEP-CVP21) [18]. These films were fabricated with 20/20 silane/diborane sccm ratio and as such a high peak doping conc. of $1.2 \times 10^{20} \mathrm{~cm}^{-3}$ is observed for the as-deposited case. The profile has a gradient across the depth of the film and a junction depth (i.e. interface between the deposited film and substrate) of $1.1 \mu \mathrm{m}$. The gradient is due to doping contribution from the boron desorption from the inner walls of the chamber. At the beginning of the deposition all surfaces inside the chamber are free from boron, as the deposition carries on boron is deposited on the surfaces and a fraction of it desorps contributing to the doping of the film [19]. The significant impact of the $4 \mathrm{~h}$ anneal is observable with reduced peak conc. of $1.6 \times 10^{19} \mathrm{~cm}^{-3}$ and a junction depth of $2.9 \mu \mathrm{m}$. The profile in this case is more complex due to both the coalescence of film and the dopants diffusing. To characterise the emitter saturation current $\left(\mathrm{J}_{0 \mathrm{e}}\right)$, of the annealed sample, Quasi Steady State Photoconductance measurements (Sinton WCT-120) were undertaken using the high injection level method proposed by Kane and Swanson [20]. The sample used for this measurement had HWCVD films deposited on both sides of the substrate followed by the $4 \mathrm{~h}$ post-anneal. The samples were then coated with a $17 \mathrm{~nm} \mathrm{Al}_{2} \mathrm{O}_{3}$ layer formed using atomic layer deposition. This passivation layer was activated using a 30 minute anneal at $400^{\circ} \mathrm{C}$. Fig. $4 \mathrm{~b}$ shows the effective lifetime $\left(\tau_{\text {eff }}\right)$ as a function the excess carrier concentration $\Delta \mathrm{n}$. $\tau_{\text {eff }}$ is related to $\mathrm{J}_{0 \mathrm{e}}$ by equation 2 .

$$
\frac{1}{\tau_{\text {eff }}}-\frac{1}{\tau_{\text {Auger }}}=\frac{1}{\tau_{\mathrm{SRH}}}+2 \frac{\mathrm{J}_{0 \mathrm{e}}\left(\mathrm{N}_{\mathrm{D}}+\Delta \mathrm{n}\right)}{\mathrm{qn}_{\mathrm{i}}^{2} \mathrm{~W}}
$$

where $\tau_{\text {Auger }}$ is the intrinsic Auger lifetime, $\tau_{\mathrm{SRH}}$ is the defect related bulk lifetime, $\mathrm{N}_{\mathrm{D}}$ is the bulk doping concentration, $\Delta \mathrm{n}$ is the excess carrier density, $\mathrm{q}$ is the elementary charge, $\mathrm{n}_{\mathrm{i}}$ is the intrinsic carrier concentration and $\mathrm{W}$ is the sample thickness. The measurements showed a relatively low value of $\tau_{\text {eff }}=202 \mu \mathrm{s}$ and a high $\mathrm{J}_{0 \mathrm{e}}=220 \mathrm{fA} \mathrm{cm}^{-2}$ despite the alumina surface passivation. In order to understand how much of this emitter saturation current is due to surface recombination, the value of $\mathrm{J}_{0 \mathrm{e}}$ was simulated for various surface recombination velocity $(\mathrm{SRV})$ and negative fixed charge $\left(\mathrm{Q}_{\mathrm{f}}\right)$ at the surface. This was undertaken using the freeware emitter modelling tool EDNA [21] which utilises the doping profile obtained from the ECV measurements. Fig. 4c shows the simulated $\mathrm{J}_{0 \mathrm{e}}$ as a function of the SRV for both the asdeposited and annealed diffusion profile. The as-deposited film exhibits a lower $\mathrm{J}_{0 \mathrm{e}}$ value until a certain value of SRV (approx $5 \times 10^{3} \mathrm{~cm} \mathrm{~s}^{-1}$ ). This is due to the higher peak doping concentration in the as-deposited emitter shielding the carriers from the surface and therefore reducing the surface recombination. As the SRV values reduce, Auger recombination becomes dominant and $\mathrm{J}_{0 \mathrm{e}}$ saturates to a minimum. The minimum $\mathrm{J}_{0 \mathrm{e}}$ for the annealed case $\left(5 \mathrm{fA} \mathrm{cm}^{-2}\right)$ is significantly lower than for the as-deposited case $\left(116 \mathrm{fA} \mathrm{cm}^{-2}\right)$ due to the high Auger recombination in the latter.

\section{TCAD MODEL}

Having illustrated the feasibility of the deposited films for use as an emitter, we focus on the design of an epitaxial IBC cell and in-particular its performance under varying surface and bulk recombination conditions. The design of the IBC cell is based on emitter fingers formed with the doping profiles shown in Fig. 4a, in-conjunction with localised diffusion for the N-type back surface field as well as localised contact holes. The input parameters of the IBC device are summarised in

TABLE II: Input parameters for 3D TCAD model of IBC cell. The parameters with * are varied in the simulations.

\begin{tabular}{cc}
\hline Cell Thickness & $280 \mu \mathrm{m}$ \\
Emitter Width & $320 \mu \mathrm{m}$ \\
Emitter thickness & $0.5 \mu \mathrm{m}$ (based on annealed structure) \\
BSF radius & $15 \mu \mathrm{m}$ \\
Contact Radius/Pitch & $5 \mu \mathrm{m} / 70 \mu \mathrm{m}$ \\
N/P Finger length & $280 \mu \mathrm{m} / 130 \mu \mathrm{m}$ \\
Bulk Doping & $8.5 \times 10^{14} \mathrm{~cm}^{-3}$ \\
Emitter Doping* & Taken from ECV for annealed structure \\
BSF Doping & Peak $=8 \times 10^{19} \mathrm{~cm}^{-3}$, Depth $=1.5 \mu \mathrm{m}$ \\
FSF Doping & none \\
Bulk Lifetime* & $10 \mu$ to $5000 \mu \mathrm{s}$ \\
Epitaxial Lifetime* & $10 \mu$ to $5000 \mu \mathrm{s}$ \\
Auger Model & Altermatt $[23]$ \\
Mobility Model & Klaassen [24] \\
$\mathrm{n}_{\mathrm{i}, \text { eff }}$ & $9.65 \times 10^{9} \mathrm{~cm}^{-3}$ \\
Front SRV & $2 \mathrm{~cm} \mathrm{~s}^{-1}$ \\
Front $\mathrm{Q}_{\mathrm{f}}$ & $5 \times 10^{11} \mathrm{~cm}^{-3}$ \\
Rear SRV & $1 \mathrm{~cm} \mathrm{~s}^{-1}$ to $1 \times 10^{7} \mathrm{~cm} \mathrm{~s}^{-1}$ \\
Rear $\mathrm{Q}_{\mathrm{f}}^{*}$ & $\pm 1 \times 10^{10} \mathrm{~cm}^{-3}$ to $\pm 1 \times 10^{14} \mathrm{~cm}^{-3}$ \\
\hline
\end{tabular}



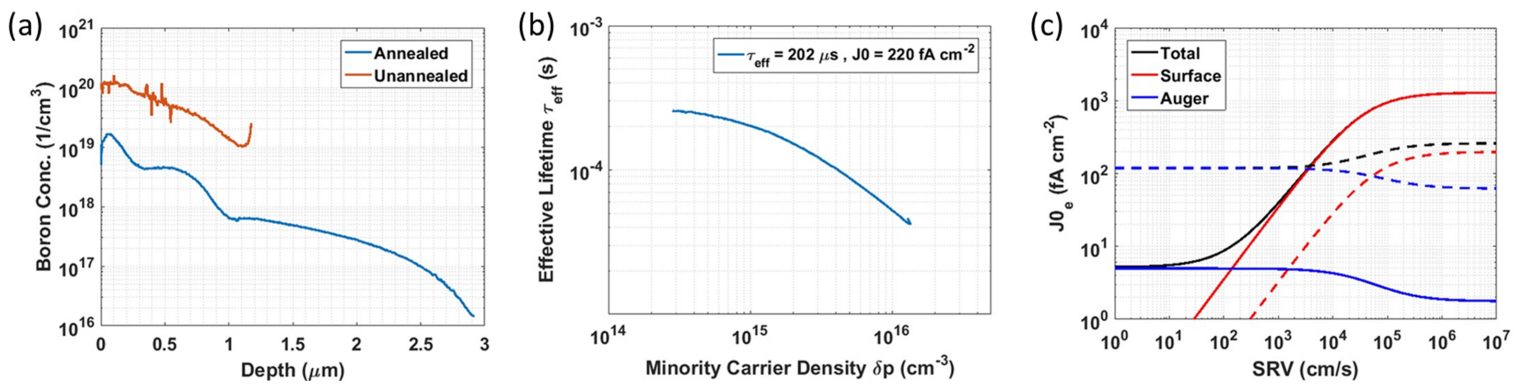

Fig. 4: a) ECV measurements of as-deposited and 4 hour annealed film using a diborane/silane ration of 20/20. b) QSSPC measurement of the annealed film. c) $\mathrm{J}_{0 \mathrm{e}}$ as function of SRV calculated using EDNA for the as-deposited doping profile (dashed line) and annealed doping profile (solid line), showing the impact of Auger and surface recombination.

Table II, and are based on an optimised device presented in [25]. The device models used follow those described in [26]. The 3D model is illustrated in Fig. 5.

The device simulation is solved using Sentaurus Device which calculates the current-voltage characteristic using the Poisson equation coupled to the drift-diffusion transport equations. Auger and Shockley Read Hall bulk and surface recombination mechanisms are taken into account in this device model. The TCAD simulation can be used to quantify the surface passivation needed in order to optimise the performance of this epitaxial IBC cell. Surface recombination is calculated in Sentaurus Device using equation 3.

$$
\mathrm{R}_{\text {surf,net }}^{\mathrm{SRH}}=\frac{\mathrm{np}-\mathrm{n}_{\mathrm{i}, \mathrm{eff}}^{2}}{\left(\mathrm{n}+\mathrm{n}_{1}\right) / \mathrm{s}_{\mathrm{p}}+\left(\mathrm{p}+\mathrm{p}_{1}\right) / \mathrm{s}_{\mathrm{n}}}
$$

where: $n_{1}=n_{i, \text { eff }} \mathrm{e}^{\frac{E_{\text {trap }}}{k T}}, p_{1}=p_{i, e f f} e^{\frac{-E_{\text {trap }}}{k T}}, n_{i, \text { eff }}$ is the intrinsic carrier concentration, $s_{p, n}$ is the surface recombination velocity (SRV). $\mathrm{E}_{\text {trap }}$, the trap energy, is used to define fixed charges $\mathrm{Q}_{\mathrm{f}}$ [27]. Fig 6a shows the efficiency, $\eta$, of the IBC cell as a function of $\mathrm{s}_{\mathrm{p}, \mathrm{n}}$ and $\mathrm{Q}_{\mathrm{f}}$. It shows that for $\mathrm{s}_{\mathrm{p}, \mathrm{n}}<1 \times 10^{2} \mathrm{~cm} / \mathrm{s}$ it is relatively insensitive to changes in the number of fixed charges. However, given values for $1 \times 10^{2}>\mathrm{s}_{\mathrm{p}, \mathrm{n}}<1 \times 10^{4} \mathrm{~cm} / \mathrm{s}, Q_{\mathrm{f}}> \pm 1 \times 10^{12} \mathrm{~cm}^{-3}$ is needed to achieve high efficiency. The figure, which supports the result shown in EDNA, indicates the performance of the IBC cell is heavily dominated by surface defects, with a poorly passivated surface $\left(\mathrm{s}_{\mathrm{p}, \mathrm{n}}>1 \times 10^{4} \mathrm{~cm} / \mathrm{s}\right.$, $\mathrm{Q}_{\mathrm{f}}< \pm 1 \times 10^{11} \mathrm{~cm}^{-3}$ ) achieving $\eta<10 \%$ whilst a well passivated surface $\left(\mathrm{s}_{\mathrm{p}, \mathrm{n}}<1 \times 10^{2} \mathrm{~cm} / \mathrm{s}, \mathrm{Q}_{\mathrm{f}}> \pm 1 \times 10^{12} \mathrm{~cm}^{-3}\right)$ achieving $\eta>25 \%$. Given that alumina coatings have been proven as a surface passivation means [22] for boron doped emitters, the low lifetime shown in Fig $4 \mathrm{~b}$ is likely due to defects within the deposited layer or interface between the deposited layer and substrate. In order to explore this further Fig $6 \mathrm{~b}$ shows the efficiency of the IBC cell as a function of bulk lifetime, $\tau_{\text {bulk }}$, and epitaxial lifetime,$\tau_{\text {epi }}$. This shows that whilst efficiency improves dramatically with increasing $\tau_{\text {bulk }}$, it is insensitive to $\tau_{\text {epi }}$. A slight drop in $\eta$ is shown for $\tau_{\text {epi }}<50 \mu \mathrm{s}$ and $\tau_{\text {epi }}>500 \mu \mathrm{s}$ which is due to loss in $V_{o c}$. As the wafers used in this work were float zone, with $\tau_{\text {bulk }}>5 \mathrm{~ms}$, it is suggested that the low lifetime observed in Fig. $4 \mathrm{~b}$ is due to defects at the interface between the deposited layer and the substrate. To explore this, we model efficiency as

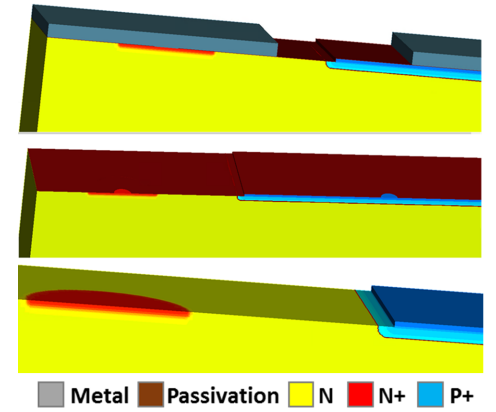

Fig. 5: 3D view of the back contact in the IBC unit cell in the TCAD model. It is shown with metallised contact layer, passivated layer and diffused regions exposed.

a function of $s_{p, n}^{\text {int }}$, i.e. the SRV at the interface of the epitaxial layer and substrate. Fig $6 \mathrm{c}$ shows that defects in this region can signifcantly reduce the efficiency of the epitaxial IBC cell, with $\mathrm{s}_{\mathrm{p}, \mathrm{n}}^{\mathrm{int}}<1 \times 10^{3} \mathrm{~cm}^{-3}$ needed to achieve a highly efficient cell. Given the use of alumina passivation (low $s_{p, n}$, high $Q_{f}$ ) and $\mathrm{Fz}$ substrate (high $\tau_{\text {bulk }}$ ), as used in this work, a best and worst case scenario of $\eta=25 \%$ ( low $\mathrm{s}_{\mathrm{p}, \mathrm{n}}^{\mathrm{int}}$ and high $\tau_{\text {epi }}$ ) and $\eta=21 \%$ ( high $\mathrm{s}_{\mathrm{p}, \mathrm{n}}^{\mathrm{int}}$ and low $\tau_{\text {epi }}$ ) is shown with this TCAD model. These modelling results indicate that experimental development of the HWCVD recipe for emitter deposition should focus on optimizing the emitter-substrate interface.

\section{CONCLUSION}

Morphology and electrical measurements have shown that the material deposited by HWCVD significantly improves with a post-deposition annealing treatment and by increasing the diborane flow rate. After annealing, the morphology improved with surface roughness reduced by $30 \%$ and denser, more uniform films present. This translated to improvements in estimated $V_{o c}$ and rectification of the junction. A 2-diode model fit of the electrical characteristics showed that increasing the diborane flow rate reduced the saturation current and ideality factor and increased the shunt resistance. ECV measurements of deposited film with a high diborane flow rate showed a reduced peak doping concentration and larger diffused junction post-anneal compared to the as-deposited sample. Using 
(a)

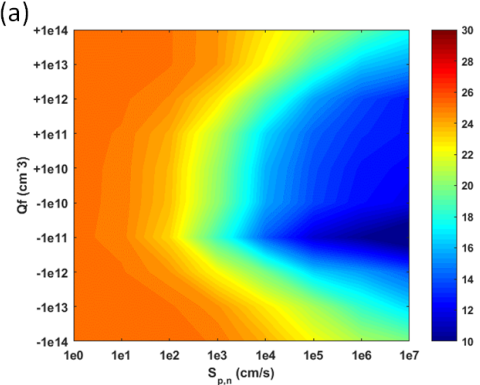

(b)

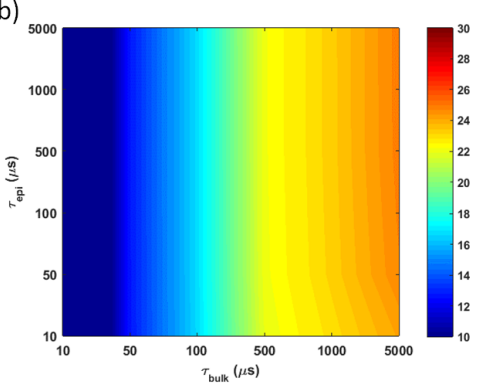

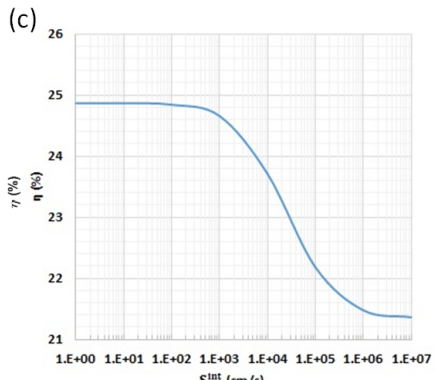

Fig. 6: a) 2D contour plot illustrating efficiency of the IBC cell as function of surface recombination and fixed charge. b) 2D contour plot illustrating efficiency of the IBC cell as a function of lifetime in the epitaxial and substrate. c) Line plot illustrating efficiency as a function of recombination at the epitaxial and substrate interface.

EDNA, the doping profiles showed that a significantly lower $\mathrm{J}_{0 \mathrm{e}}$ can be achieved for the annealed case due to the high Auger recombination present in the as-deposited case. QSSPC measurements showed $\mathrm{J}_{0 \mathrm{e}}=220 \mathrm{fA} \mathrm{cm}^{-2}$ and $\tau_{\text {eff }}=200 \mu \mathrm{s}$. TCAD modelling of the epitaxial IBC cell showed that defects between the epitaxial layer and the substrate are the dominant limiting factor and that an optimized device can lead to power conversion efficiencies approaching $25 \%$.

\section{ACKNOWLEDGMENT}

T. Rahman and S.A. Boden acknowledge support from the Supersolar Solar Energy Hub (EPSRC grants EP/J017361/1 and EP/M014797/1). The data from this paper can be obtained from University of Southampton e-Prints repository (http://dx.doi.org/10.5258/SOTON/398598).

\section{REFERENCES}

[1] Kerschaver, E. V., \& Beaucarne, G. (2006). Backcontact solar cells: A review. Progress in Photovoltaics: Research and Applications, 14(2), 107-123.

[2] Yang, X., Muller, R., Xu, L., Bi, Q., Weber, K., Franklin, E., \& Benick, J. (2015). Ion-Implanted Laser-Annealed p+ and n+ Regions: A Potential Solution for Industrially Feasible High-Efficiency N-Type Interdigitated Back-Contact Solar Cells. Photovoltaics, IEEE Journal of, 5(1), 87-93.

[3] Green, M. A., Emery, K., Hishikawa, Y., Warta, W., and Dunlop, E. D. (2016) Solar cell efficiency tables (version 47). Prog. Photovolt: Res. Appl., 24: 311. doi: 10.1002/pip.2728.

[4] Schmich, E., Driessen, M., Kiefer, F., Hampel, J., \& Reber, S. (2009, June). In-situ CVD processes for crystalline silicon thin-film solar cells. In Photovoltaic Specialists Conference (PVSC), 2009 34th IEEE (pp. 000175-000180). IEEE.

[5] Recaman Payo, M., Posthuma, N., de Castro, A. U., Debucquoy, M., \& Poortmans, J. (2014). Boron-doped selective silicon epitaxy: high efficiency and process simplification in interdigitated back contact cells. Progress in photovoltaics, 22(7), 711-725.

[6] Van Nieuwenhuysen, K., Recaman Payo, M., Kuzma-Filipek, I., Van Hoeymissen, J., Van Kerschaever, E., \& Poortmans, J. (2009, June). Epitaxial thin film silicon solar cells with CVD grown emitters exceeding $16 \%$ efficiency. In Photovoltaic Specialists Conference (PVSC), 2009 34th IEEE (pp. 000933-000936). IEEE.

[7] Rachow, T., Milenkovic, N., Steinhauser, B., Benick, J., Janz, S., Hermle, M., \& Reber, S. (2015). Solar Cells with Epitaxial or Gas Phase Diffused Emitters Above 21\% Efficiency. Energy Procedia, 77, 540-545.

[8] Ishibashi, K., Karasawa, M., Xu, G., Yokokawa, N., Ikemoto, M., Masuda, A. and Matsumura, H., 2003. Development of Cat-CVD apparatus for 1-m-size large-area deposition. Thin Solid Films, 430(1), pp.58-62.

[9] Wang, Q., Teplin, C.W., Stradins, P., To, B., Jones, K.M. and Branz, H.M., 2006. Significant improvement in silicon chemical vapor deposition epitaxy above the surface dehydrogenation temperature. Journal of applied physics, 100(9), p.093520.
[10] Savin, H., Repo, P., von Gastrow, G., Ortega, P., Calle, E., Garn, M., \& Alcubilla, R. (2015). Black silicon solar cells with interdigitated back-contacts achieve $22.1 \%$ efficiency. Nature nanotechnology.

[11] Jeong, S., McGehee, M. D., \& Cui, Y. (2013). All-back-contact ultra-thin silicon nanocone solar cells with $13.7 \%$ power conversion efficiency. Nature communications, 4.

[12] Zin, N., Blakers, A., McIntosh, K. R., Franklin, E., Kho, T., Chern, K., \& Verlinden, P. J. (2013). Continued development of all-back-contact silicon wafer solar cells at ANU. Energy Procedia, 33, 50-63.

[13] Viera, G., Huet, S., \& L. Boufendi (2001). Crystal size and temperature measurements in nanostructured silicon using Raman spectroscopy. Journal of Applied Physics, 90, 4175-4183.

[14] Nickel, N. H. , Lengsfeld, P. \& Sieber, I. (2000). Raman spectroscopy of heavily doped polycrystalline silicon thin films, Physical Review B, 61, 15558-15561.

[15] Branz, H.M., Teplin, C.W., Romero, M.J., Martin, I.T., Wang, Q., Alberi, K., Young, D.L. and Stradins, P., (2011). Hot-wire chemical vapor deposition of epitaxial film crystal silicon for photovoltaics. Thin Solid Films, 519(14), pp.4545-4550.

[16] Suckow S., 2/3-Diode Fit (2014). http://nanohub.org/resources/14300

[17] Wolf M., Rauschenbach H. Series resistance effects on solar cell measurements. Advanced Energy Conversion 1963; 3(2): 455-479

[18] Peiner, E., Schlachetzki, A., \& Krger, D. (1995). Doping Profile Analysis in Si by Electrochemical CapacitanceVoltage Measurements. Journal of the Electrochemical Society, 142(2), 576-580. Chicago

[19] Martin, I. T., Branz, H. M., Stradins, P., Young, D. L., Reedy, R. C., \& Teplin, C. W. (2009). Doping of high-quality epitaxial silicon grown by hot-wire chemical vapor deposition near $700 \mathrm{C}$. Thin Solid Films, 517(12), 3496-3498.

[20] Kane DE, Swanson R.M. Measurement of the emitter saturation current by a contactless photoconductivity decay method (silicon solar cells). Proceedings of the 18th IEEE Photovoltaic Specialists Conference, 1985; 578583.

[21] McIntosh, K. R., \& Altermatt, P. P. (2010, June). A freeware 1D emitter model for silicon solar cells. In Photovoltaic Specialists Conference (PVSC), 2010 35th IEEE (pp. 002188-002193). IEEE. Chicago

[22] Liao, B., Stangl, R., Ma, F., Hameiri, Z., Mueller, T., Chi, D. \& Hoex, B. (2013). Deposition temperature independent excellent passivation of highly boron doped silicon emitters by thermal atomic layer deposited A12O3. Journal of Applied Physics, 114(9), 094505.

[23] Altermatt, P.P., Schmidt, J., Heiser, G., \& Aberle, A.G.(1997) Assessmentand parameterisation of Coulomb-enhanced Auger recombinationcoefcients in lowly injected crystalline silicon. J. Appl. Phys.82(10), 49384944

[24] Klaassen, D. B. M. (1992). A unified mobility model for device simulationI. Model equations and concentration dependence. SolidState Electronics, 35(7), 953-959.

[25] Franklin, E., Fong, K., McIntosh, K., Fell, A., Blakers, A., Kho, T., \& Wang, E. C. (2014). Design, fabrication and characterisation of a $24.4 \%$ efficient interdigitated back contact solar cell. Progress in Photovoltaics: Research and Applications.

[26] Fell, A., McIntosh, K. R., Altermatt, P. P., Janssen, G. J., Stangl, R., HoBaillie, A., \& Fong, K. C. (2015). Input parameters for the simulation of silicon solar cells in 2014. Photovoltaics, IEEE Journal of, 5(4), 1250-1263.

[27] Sentaurus Device User Guide. (2013) http://www.synopsys.com 